\title{
COMPARATIVE ANALYSIS OF THE SHRINKAGE STRESS OF COMPOSITE RESINS
}

\author{
Rosana Aparecida PEREIRA ${ }^{1}$, Paulo Amarante de ARAUJO ${ }^{2}$, \\ Juan Carlos CASTAÑNEA-ESPINOSA ${ }^{3}$, Rafael Francisco Lia MONDELLI ${ }^{4}$
}

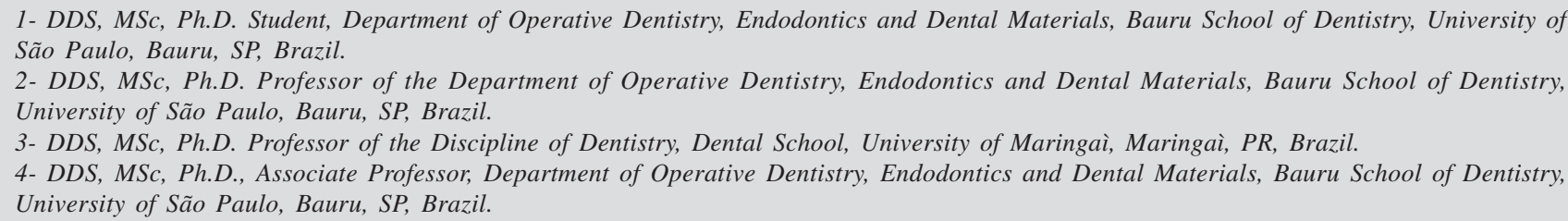

Corresponding address: Rosana Aparecida Pereira, Universidade de São Paulo, Faculdade de Odontologia de Bauru - Alameda Dr. Octávio Pinheiro Brisolla, 9-75 - 17 012-301, Bauru, SP, Brazil. Phone: 55-14-3235-8263 - e-mail: rosanapbc@ yahoo.com.br

Received: April 2, 2007 - Modification: August 20, 2007 - Accepted: October 24, 2007

\begin{abstract}
$\Gamma_{\text {he }}$ he aim of this study was to compare the shrinkage stress of composite resins by three methods. In the first method, composites were inserted between two stainless steel plates. One of the plates was connected to a $20 \mathrm{kgf}$ load cell of a universal testing machine (EMIC-DL-500). In the second method, disk-shaped cavities were prepared in 2-mm-thick Teflon molds and filled with the different composites. Gaps between the composites and molds formed after polymerization were evaluated microscopically. In the third method, the wall-to-wall shrinkage stress of the resins that were placed in bovine dentin cavities was evaluated. The gaps were measured microscopically. Data were analyzed by one-way ANOVA and Tukey's test $(\alpha=0.05)$. The obtained contraction forces were: Grandio $=12.18 \pm 0.428 \mathrm{~N}$; Filtek Z $250=11.80 \pm 0.760 \mathrm{~N}$; Filtek Supreme $=11.80 \pm 0.707$ $\mathrm{N}$; and Admira $=11.89 \pm 0.647 \mathrm{~N}$. The gaps obtained between composites and Teflon molds were: Filtek Z 250 $=0.51 \pm 0.0357 \%$; Filtek Supreme $=0.36 \pm 0.0438 \%$; Admira $=0.25 \pm 0.0346 \%$ and Grandio $=0.16 \pm 0.008 \%$. The gaps obtained in wall-to-wall contraction were: Filtek Z $250=11.33 \pm 2.160 \mu \mathrm{m}$; Filtek Supreme $=10.66 \pm 1.211 \mu \mathrm{m}$; Admira $=11.16 \pm 2.041 \mu \mathrm{m}$ and Grandio $=$ $10.50 \pm 1.224 \mu \mathrm{m}$. There were no significant differences among the composite resins obtained with the first (shrinkage stress generated during polymerization) and third method (wall-to-wall shrinkage). The composite resins obtained with the second method (Teflon method) differed significantly regarding gap formation.
\end{abstract}

Uniterms: Composite resins. Shrinkage stress. Polymerization. Polymerization contraction.

\section{INTRODUCTION}

In the last two decades, the large number of studies involving composite resins in different countries led these materials to improved mechanical properties and esthetics. However, they still present the contraction during polymerization process as a major problem. This shrinkage can be understood as a densification or loss of volume ${ }^{18,23}$. Differently from what would happen if resins were polymerized in the air, within a cavity, this type of contraction does not occur freely ${ }^{9}$. The shrinkage forces internally generated in the material are partially transmitted to the tooth-restoration adhesive interface compromising the marginal integrity. Consequently, the restoration becomes more susceptible to microleakage and postoperative sensitivity $8,10,20,21$

In an attempt to improve the physical properties of composite resins, the extent of their polymerization contraction has been extensively investigated. Since Bowen ${ }^{5}$ (1967) introduced Bis-GMA (bisphenol glycidyl dimethacrylate) as the monomer system for dental composites in the mid-1960's, resin composition has changed leading to superior physical, chemical and mechanical properties as well as clinical longevity.

One of the promising contributions, in this sense, refers to the use of nanotechnology in novel material formulation. It consists in the production of materials and functional structures in the range of 0.1 to $100 \mathrm{~nm}$ (nanoscale). This is done through several physical and chemical methods where quartz, glass and ceramic fillers are converted in nanofillers ${ }^{25}$. Higher filler content in composites reduces shrinkage stress. The use of Ormocer as the matrix in composites is considered as an alternative method in obtaining low-shrinkage resins with improved clinical performance. Ormocer is based on an 
organically modified ceramic presenting an inorganic structure (framework - silicon network - oxygen) inside the organic matrix ${ }^{26}$.

The resin matrix is responsible for the polymerization process ${ }^{18}$ in which monomer reaction forms covalent bonds. The distance between two monomers is around 0.3 to 0.4 $\mathrm{nm}$ (van der Waals distance). Volumetric shrinkage (1.5 to $3 \%$ ) during material polymerization and density increase results from the conversion of these van der Waals distances between monomers to covalent bond lengths $(0.15 \mathrm{~nm})$. This is an inherent and inevitable phenomenon ${ }^{22}$

In view the importance of the shrinkage stress in adhesive restorations, the aim of this study was to evaluate this shrinkage stress behavior as a function of different composite resins using three methods.

\section{MATERIAL AND METHODS}

In the present study, the shrinkage stress of 4 composite resins, were examined by three methods: evaluation of the shrinkage stress generated during polymerization, free linear shrinkage and wall-to-wall shrinkage.

The tested composite resins: Filtek Z250 (microhybrid; 3M/ESPE, St. Paul, MN, USA), Filtek Supreme (nanofilled; 3M/ESPE), Admira (an Ormocer-based material; Voco, Cuxhaven, Germany) and Grandio (nanohybrid; Voco), with their respective adhesive systems, Single Bond (3M/ESPE), Admira Bond (3M/ESPE), Solobond (Voco).

\section{Evaluation of the Shrinkage Stress Generated During Polymerization}

The shrinkage stress, were recorded by a universal testing machine (EMIC, DL 500 BF-NO5775-NS168, São José dos Pinhais, PR, Brazil). Two opposite and parallel stainless steel plates were fabricated. The bottom plate (cylindrical) was fixed and connected to a Bencor Multitest device especially adapted for this test. The top plate (rectangular) was free to move and connected to a $20 \mathrm{kgf}$ load cell of a computerized testing machine $\mathrm{e}^{20,21}$.

Composite resins were placed between the plates at a distance of $6 \mathrm{~mm}$ and a width of $2 \mathrm{~mm}$. The test was performed simultaneously to the composite resins photoactivated with a halogen light-curing unit (Degulux; Degussa Hüls, Frankfurt, Germany) during $20 \mathrm{~s}$ with light intensity of 500 $\mathrm{mW} / \mathrm{cm}^{2}$ verified by a curing radiometer (model 100 ; Demetron Research Corp., Danbury, CT, USA). The lightcuring unit tip was positioned close to the specimen's wider surface $(6 \mathrm{~mm})$ to assure an uniform irradiation $(2 \mathrm{~mm}$ diameter). For each composite resin, 10 tests were performed. During test, the shrinkage stress generated by polymerizing the composite caused a minimal deflection in load cell, which was transmitted to the testing machine. Each test produced a force $(\mathrm{N}) \mathrm{X}$ time $(\mathrm{s})$ graph. The maximum shrinkage stress obtained for each test, were recorded.

\section{Evaluation of Free Linear Shrinkage (\%)}

The present study also evaluated the composite resin in vitro free linear shrinkage. For this test, Teflon molds with rectangular cavities (12 mm length X $5 \mathrm{~mm}$ width X $2 \mathrm{~mm}$ height) and rounded internal line angles were used. Teflon molds were chosen because they do not react with composite resins allowing them to freely shrink in the cavities during polymerization. Unpolymerized material was applied to molds, which were covered on both sides with a polyester matrix strip and a rigid microscope glass slide. Specimens were light cured with the halogen light-curing unit (Degulux, Degussa) at a light intensity of $500 \mathrm{~mW} / \mathrm{cm}^{2}$, which was verified by the curing radiometer (model 100; Demetron Research Corp. ) before every curing cycle.

To obtain a flat surface, each specimen was polymerized under pressure during $40 \mathrm{~s}$ with the light-curing unit tip (7 $\mathrm{mm}$ diameter) positioned on its center, and during additional $20 \mathrm{~s}$ with the tip positioned in each composite-mold interface (taking its length as reference). Subsequently, the compositemold interfaces were examined by an automatic photomicroscope at x 80 magnification. The interfacial gaps were measured using a distance or space scale $(\mu \mathrm{m})$ present in the equipment's screen. The percentage of linear shrinkage was calculated as a function of the cavity internal length by the following equation: $X(\%)=G_{(\mu \mathrm{m})} \times 100 / T_{(\mu \mathrm{m})}$, where, $\mathrm{G}_{(\mu \mathrm{m})}$ indicates the maximum gap-width together with the opposite gap and $\mathrm{T}_{(\mu \mathrm{m})}$ indicates the Teflon length $(\mu \mathrm{m})$ respectively.

Five specimens were evaluated for each composite resin. The tests were performed at a room with controlled temperature $\left(23 \pm 1{ }^{\circ} \mathrm{C}\right)$ and humidity $(65 \pm 5 \%)$.

\section{Wall-to-Wall Shrinkage}

This method was initially proposed by Asmussen and Jorgensen $^{2}$ (1972). Twenty-four bovine teeth stored in $1 \%$ chloramine $\mathrm{T}$ solution at room temperature were used. A flat enamel surface was obtained by grinding the buccal surface with wet 300, 600 and 1000 grit silicon carbide paper, until an area of at least $6 \mathrm{~mm}$ in diameter was exposed. Cylindrical cavities were prepared to a depth of approximately $1.5 \mathrm{~mm}$, with a diameter of $3.0 \mathrm{~mm}$, using a diamond cylindrical bur (2094, KG Sorensen, São Paulo, SP, Brazil) under wet conditions. Cavities were then finished with a \#57 cylindrical stainless steel bur (SS White, São Paulo, SP, Brazil) also under wet conditions. Six cavities were prepared for the evaluation of each composite resin. The cavity walls and surrounding enamel margin were treated with phosphoric acid and adhesive systems according to each composite manufacturer's instructions. The cavities were filled with the restorative materials, which were light cured (Degulux, Degussa) according to each manufacturer's instructions. After 10 minutes, specimens were stored in deionized water. Excess filling material on enamel surface was removed by wet polishing with 300-, 600- and 1000-grit silicon carbide papers to allow a proper examination of the margin gaps between dentin and restoration. Subsequently, the length of specimen's marginal gaps were observed and measured in a light microscope with a reticulate measuring ocular. Gaps were examined at the whole specimen's extension and measured at the wider point $(\mu \mathrm{m})$. From this point, the cavity 
diameters were also measured and the gaps were calculated in relation to obtained diameters.

\section{Statistical Analysis}

Data sets for shrinkage stress during photopolymerization, linear shrinkage and wall-to-wall shrinkage were each subjected to one-way ANOVA (to examine the influence of materials) and Tukey's test. Significance level was set at 0.05 .

\section{RESULTS}

The light-cured composite resins described similar force/ time graphs. As soon as the test and polymerization procedure started (simultaneously), shrinkage stress started to be generated. For all composites, it was observed that shrinkage stresses continued to be generated in increased rates for around 30 seconds after specimen irradiation time (20 seconds). After this 30-second period, the stresses decreased and were maintained constantly in slight increases up to the end of the test, 120 seconds. The maximum shrinkage stresses were recorded for analysis. Grandio nanofilled composite resin presented the highest mean value of contraction forces $(12.18 \pm 0.43 \mathrm{~N})$ but it did not differ significantly from that obtained with Filtek Z250 $(11.80 \pm 0.76 \mathrm{~N})$, Filtek Supreme $(11.80 \pm 0.71 \mathrm{~N})$ and Admira $(11.89 \pm 0.65 \mathrm{~N})$ (Table 1$)$.

ANOVA showed statistically significant differences among all composite resins with respect to the percentage of linear contraction (Table 1); Filtek Z250 presented a significantly higher percent shrinkage mean value than Filtek Supreme, Admira and Grandio. Grandio presented the lowest percent shrinkage mean value. ANOVA also showed that there were no statistically significant differences among the evaluated composite resin mean values of wall-to-wall marginal gap (Table 1).

\section{DISCUSSION}

In the present study, the polymerization shrinkage of four composite resins was evaluated by three methods. The polymerization shrinkage stresses were evaluated by an in vitro mechanical test, in which the composite resin is placed between two stainless steel plates simulating oral conditions ${ }^{27}$. In addition, the linear shrinkage in percentage was tested by an experimental model in which composites are placed in non-adherent Teflon molds. This test was first used by Bowen, et al. ${ }^{6}$ (1983). Finally, the third method analyzed the marginal gaps of restorations placed in bovine teeth dentin cavities. This method, known as wall-to-wall shrinkage, was proposed by Asmusen and Jorgensen ${ }^{2}$ (1972).

Thus, polymerization shrinkage could be observed since its origin when it occurs freely (linear shrinkage in percentage), by a laboratorial test with standardized conditions that simulates oral environment (evaluation of shrinkage stress during polymerization), and finally by observing these stress consequences in a test where restorations were placed in tooth cavities. Therefore, this study allowed comparing resins' shrinkage behavior, in both free and confined conditions, and among the three different methods used.

In both tests where composite resins was confined (shrinkage stress test and marginal gap test), there were no significant differences among the composite resin mean values. Conversely, in the free linear shrinkage method, there were significant differences among the mean values recorded for the composite resins. In the tests where composites were confined, either by the stainless steel plates or by a tooth cavity, compatible results were noted, confirming their efficiency. In addition, they can be considered simple and effective tests to obtain rapid and reliable data in different conditions. It was also observed that, for both tests, the mean values presented low standard deviations, raising their reliability. These results could be interpreted as the material having a different shrinkage behavior for each testing condition. As stated by Bausch ${ }^{3}$ (1982), during shrinkage, the resin has two options: either a free shrinkage without generating tensions or creation of tensions when the shrinkage is obstructed.

Nevertheless, these tensions are not only associated with the volumetric or linear shrinkage of the materials. They also relate to the material capacity to flow during the initial polymerization stage ${ }^{9}$, and to its flexibility in the later polymerization stage where the composite starts presenting a solid-material characteristics ${ }^{7,14,15}$. In both methods

TABLE 1- Mean values of contraction forces (N), linear contraction (\%) and wall-to-wall marginal gaps for Filtek Z250, Filtek supreme, Admira and Grandio

$\begin{array}{llll}\text { Composite Resin } & \text { Contraction } & \text { Linear contraction } & \text { Wall-to-wall marginal } \\ \text { s } & \text { forces (N) (s.d.) } & \text { (\%) (s.d.) } & \text { gap ( } \mu \text { m) (s.d.) }\end{array}$

\begin{tabular}{llll} 
Filtek Z250 & $11.80(0.76) \mathrm{a}$ & $0.516(0.04) \mathrm{a}$ & $11.33(2.16) \mathrm{a}$ \\
Filtek Supreme & $11.80(0.71) \mathrm{a}$ & $0.362(0.05) \mathrm{b}$ & $10.66(1.21) \mathrm{a}$ \\
Admira & $11.89(0.65) \mathrm{a}$ & $0.250(0.04) \mathrm{c}$ & $11.16(2.04) \mathrm{a}$ \\
Grandio & $12.18(0.43) \mathrm{a}$ & $0.160(0.00) \mathrm{d}$ & $10.50(1.22) \mathrm{a}$ \\
\hline
\end{tabular}

Different letters indicate statistically significant difference at $5 \%$ by Tukey's test; s.d.: standard deviation. 
(shrinkage stress during polymerization and marginal gap evaluation), composites are bonded to walls. In these cases, free shrinkage is partially obstructed leading to the creation of stress followed by restoration debonding and marginal gap formation. Considering that gap formation is a consequence of the stress generated during shrinkage, and all 4 evaluated materials presented similar magnitude of shrinkage stress, it was expected that there would be no significant differences among the tested composites with respect to gap formation, as demonstrated in this study. In the free linear shrinkage method, the resin shrinks freely either in length or in width, and their modulus of elasticity would not present any influence on these results. These similarities and differences among methods can explain the present results. They are in agreement with those of

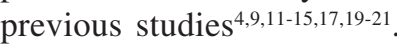

The present study verified that light-cured composites, activated with halogen lamp at $500 \mathrm{~mW} / \mathrm{cm}^{2}$ of power density, have reduced pre-gel phase. This is because an instant increase in stress after light irradiation was observed in the graphs obtained for the tested materials. Therefore, a significant compensation by the material's flow capacity and generated stress would not occur; consequently, the shrinkage stress would be transmitted to the resin-tooth interface (wall-to-wall shrinkage) since the beginning of light activation.

The magnitude of composite polymerization shrinkage stress is related to the equilibrium between adhesion stress and its contraction within a cavity ${ }^{2}$. The selection of 4 different restorative materials, in this study, was to address whether their different compositions and formulations would interfere with polymerization shrinkage and the generation of tensions. Properties, such as modulus of elasticity, polymerization shrinkage, coefficient of linear thermal expansion and water sorption, correlate directly to each material's type and composition ${ }^{1,3,7}$.

In this study, Grandio (0.16\%) presented significantly lower free linear shrinkage values than Filtek Z250 (0.51\%), Filtek Supreme $(0.36 \%)$ and Admira (0.25\%). Nevertheless, no significant differences were noted with regard to shrinkage stress.

In the wall-to-wall shrinkage, Grandio was no significantly different from the other composites either. Owing to nanotechnology, this composite resin presents higher filler loading (87 wt\%) and modulus of elasticity $(17,100 \mathrm{MPa}$, according to manufacturer's information) compared to all other tested materials. These characteristics are favorable to its physical properties. However, even having high filler loading, Grandio did not present increased shrinkage stress when evaluated in standardized conditions. The material capacity to flow during polymerization is an important characteristic to compensate shrinkage. Either the modulus of elasticity or the flow capacity depends on the material's monomer composition and inorganic filler loading. In the resins Grandio and Filtek Supreme, where nanotechnology is present, the particles type (spherical, microhybrid or nanoclustered, respectively) could apparently lead to increased creep during shrinkage, allowing to tension releases. This way, nanotechnology produces materials with high filler loading and modulus of elasticity to present low shrinkage stress. In this study, the nanofilled resins showed a similar behavior to that of Filtek Z250 and Admira, which are microhybrid composite resins and provided significantly low shrinkage stress compared to that produced by other microhybrid composites evaluated in previous studies ${ }^{21}$.

On the other hand, even demonstrating a free linear shrinkage significantly higher than Grandio and Admira, Filtek Supreme and Filtek Z250 did not present significantly higher shrinkage stress than other composites or led to higher gap formation, suggesting increased capability to release tension. With reference to Filtek Supreme, the composite presents (dispersed or clustered) nanoparticles exclusively. It has $75 \mathrm{wt} \%$ of filler loading and a modulus of elasticity of $10.500 \mathrm{MPa}$ (manufacturer's information). These are the lowest values compared to other evaluated composites.

The behavior of Filtek Z250 (78 wt $\%$ of filler loading and a modulus of elasticity of $(11,700 \mathrm{MPa}$, according to manufacturer's information) could suggest a proper balance between filler loading and material rigidity. Our results convey the influence of composite modulus of elasticity on the tension generated during linear shrinkage, elucidating that the latter exhibit the product of the linear shrinkage by the material modulus of elasticity.

When Admira was compared to other composites, it was observed that its free linear shrinkage value was the second lowest. Although Grandio had the lowest linear shrinkage value, among all composites, it did not present the best performance with regard to generation of shrinkage stress, neither marginal gap formation. Admira presents an Ormocerbased matrix. It is composed of an inorganic framework containing Bis-GMA/TEGMA polymerizable organic groups in both terminals. These inorganic molecules are longer than Bis-GMA, which could explain the material's lower volumetric shrinkage. Incorporation of filler particles decreases volumetric shrinkage. Regarding Ormocer, the shrinkage decreases from $2-8 \%$ when it has no fillers to 1 $3 \%$ when fillers are incorporated. This material presents 78 $\mathrm{wt} \%$ of filler loading and a modulus of elasticity of 10.700 $\mathrm{MPa}$ (manufacturer's information).

The present results suggest that a material with high filler loading and high modulus of elasticity presents low free shrinkage. However, when it is bonded to cavity walls, where the shrinkage is obstructed (under stress), the material can generate stresses against its own shrinkage leading to results that agree with those of $\operatorname{Suh}^{24}$ (2000) and Tessore and Trinchero ${ }^{25}$ (2001). Future studies should address the questions related to the stress caused by composite contraction on tooth cusps. It is also suggested that marginal gaps in the free linear shrinkage and wall-to-wall methods should be, if possible, analyzed by a three-dimensional method. In the present study, gaps were analyzed on the specimen's top surface limiting the accuracy of the contraction measurements. 


\section{CONCLUSIONS}

- There were no significant differences among evaluated composite resins regarding the magnitude of shrinkage stress generated during polymerization.

- There were significant differences among evaluated composite resins regarding the marginal gaps generated in free linear shrinkage. Z250 microhybrid composite resin presented the highest marginal gap mean value, followed by Filtek Supreme nanofilled composite resin and Admira Ormocer-based composite resin Admira. Grandio nanofilled composite resin presented the lowest marginal gap mean value obtained after free-linear polymerization in Teflon molds.

- There were no significant differences among evaluated composite resins regarding the marginal gaps generated in wall-to-wall shrinkage.

\section{ACKNOWLEDGEMENTS}

This study was partially supported by grants from CAPES, Brazil.

\section{REFERENCES}

1- Asmussen E. Marginal adaptation of restorative resins in acid etched cavities. Acta Odont Scand. 1976;35:125-34

2- Asmussen E, Jorgensen KD. A microscopic investigation of the adaptation of the adaptation of some plastic filling materials to dental cavity walls. Acta Odontol Scand. 1972;30:3-21.

3- Bausch JR, de Lange K, Davidson CL, Peters A, de Gee AJ. Clinica significance of polymerization shrinkage of composite resins. J Prosthet Dent. 1982;48:59-67.

4- Bouschlicher MR, Vargas MA, Boyer DB. Effect of composite type, light intensity, configuration factor and laser polymerization on polymerization contraction forces. Am J Dent. 1997;10:88-96.

5- Bowen RL. Adhesive bonding of various materials to hard tooth tissues VI. Forces developing in direct-filling materials during hardening. J Am Dent Assoc. 1967;74:439-44.

6- Bowen RL, Nemoto K, Rapson JE. Adhesive bonding of various materials to hard tooth tissues: forces developing in composite materials during hardening. J Am Dent Assoc. 1983;106:475-7.

7- Braem M, Lambrechts P, Vanherle G, Davidson CL. Stiffness increase during the setting of dentistry composite resins. J Dent Res.1987;66:1713-6.

8- Davidson CL. Resisting the curing contraction with adhesive composites. J Prosthet Dent. 1986;55:446-7.

9- Davidson CL, De Gee AJ. Relaxation of polymerization contraction stresses by flow in dental composites. J Dent Res. 1984;63:146-8.

10- Davidson CL, De Gee AJ, Fellzer AJ. The competition between the composite-dentin bond strength and the polymerization contraction stress. J Dent Res. 1984;63:1396-9.
11 - Fellzer AJ, De Gee AJ, Davidson CL. Setting stress in composite resin in relation to configuration of the restoration.J Dent Res. $1987 ; 66: 1636-9$

12- Hansen EK, Asmussen E. Marginal adaptation of posterior resins: Effect of dentin-bonding agent and hygroscopic expansion. Dent Mater. 1989;122-6.

13 - Hegdahl T, Gjerdet NR. Contraction stresses of composite resin filling materials. Acta Odontol Scan. 1977;354:191-5.

14- Kemp-Scholte CM, Davidson CL. Marginal sealing of curing contraction gaps in class $\mathrm{V}$ composite resin restorations. J Dent Res. 1988;67:841-5.

15- Kemp-Scholte CM, Davidson CL. Complete marginal seal of class V resin composite restorations effected by increased flexibility. J Dent Res. 1990;69:1240-3.

16- Kemp-Scholte CM, Davidson CL. Marginal integrity related to bond strength and strain capacity of composite resin restorative systems. J Prosthet Dent. 1990;64;658-64.

17- Koran P, Kurschner R. Effect of sequential versus continuous irradiation of light-cure resin composite on shrinkage, viscosity, adhesion, and degree of polymerization. Am J Dent. 1998;11:17-22.

18 - Lenhard M. Composite Restorations. Ivoclar Vivadent Clinical. Liechtenstein 2001;1.

19- Meredith N, Setchell DJ. In vitro measurement of cuspal strain and displacement in composite restored teeth. J Dent. 1997;25:3317.

20- Mondelli RFL, Ishikiriama SK, Valeretto TM, Franco EB, Ishikiriama A, Mondelli J. Força de contraçâo de polimerização de materiais de forramento e resina composta. Rev Assoc Paul Cir Dent. 2006;60:61-6

21 - Pereira RA, Amarantes AP, Castañeda-Espinosa JC. Avaliação de contração de polimerização de resinas compostas: microhíbrida, nanopartículas e ormocer. Rev Ibero Am de Odont Est \& Dent JBD. $2005 ; 4: 181-7$

22-Rueggeberg F. Contemporary issues in photocuring. Comp Continuing Educ Dent. 1999;20:4-15.

23- Sakaguchi RL, Wiltbank BD, Shah NC. Critical configuration analysis of four methods for measuring polymerization shrinkage strain of composites. Dent Mater. 2004;20:388-96.

24-Suh BI. Understanding and controlling the effect of polymerization shrinkage stress in composite restorations. Atti Italy Probagonsti in Odontoiatria. 2000:60-7.

25- Tessore G, Trinchero A. Post-operative sensitivity consequent to composite restorations in posterior sectors. Atti Italy Probagonsti in Odontoiatria. 2001:62-5.

26- Wolter H. Bulk Ormocer and ormocer composites. Annual report 1995. Fraunhofer Institut für Silicatforsghung. 1995:45-51.

27-Zanchi CH, Carvalho RV, Rodrigues JSA, Demarco F, Burnett JLH. Shrinkage stress of three composites under different polymerization methods. Braz Oral Res. 2006;20:137-42. 